\title{
ASPEK REPRODUKSI IKAN KURISI BALI (Pristipomoides typus) DARI PERAIRAN KEI KECIL, MALUKU TENGGARA
}

\author{
Retno Andamari"), Sjahrul Bustaman**), dan Hasmi Banjar ${ }^{* * *}$
}

\begin{abstract}
ABSTRAK
Dalam rangka menunjang budi daya laut dan juga pengelolaan perikanan tangkap maka perlu diketahui pula aspek reproduksi jenis-jenis ikan ekonomis penting. Salah satu diantaranya ikan kurisi Bal (Pristipomoides typus). Untuk itu maka dilakukan penelitian aspek reproduksi ikan kurisi Bali di Tual Perairan Kei Kecil, Maluku Tenggara. Sampling dilaksanakan dari bulan Juni 1999 sampai dengan April 2000. Dalam periode tersebut diperoleh sejumlah 150 ekor yang 86 di antaranya dewasa. Berdasarkan analisa histologi maka dapat disimpulkan bahwa ikan ini mempunyai perkembangan oosit yang bersifat asinkronus. Fekunditas relatif berkisar 115-340 butir dengan rata-rata 184 butir dan rata-rata fekunditas per angkatan 115.886 butir. Hubungan panjang berat menunjukkan nilai $b=2,77\left(R^{2}=0,97\right)$.
\end{abstract}

\begin{abstract}
Reproductive aspect of sharptooth snapper (Pristipomoides typus) from Kei Kecil waters, South-East Maluku. By: Retno Andamari, Sjahrul Bustaman, and Hasmi Banjar

In order to support marine culture and its fishery management the reproductive aspect of some species fish are an important component. The most important reproductive aspect of fish such as sharptooth snapper (Pristipomoides typus) was studied in Tual, Kei Kecil waters, South-East Maluku from June 1999 until April 2000. In this sampling periode, we collected 150 Pristipomoides typus. A number has developed gonads. From histological analysis this species is a multiple spawner with asynchronous oocyte development. The relative fecundity ranged between 115 to 340 (the average 184) and average batch fecundity 115,886 . The length weight relationship has a value of $b$ less than $3\left(b=2.77 ; R^{2}=0.97\right.$.
\end{abstract}

KEYWORDS: Pristipomoides typus, fecundity, length-weight

\section{PENDAHULUAN}

Dalam rangka menunjang budi daya laut dan pengelolaan perikanan tangkap maka perlu diketahui pula aspek reproduksi jenis-jenis ikan yang menjadi target species. Di kawasan bagian timur Indonesia terutama di Laut Arafura jenis ikan yang dominan adalah ikan kakap merah (Lutjanus malabaricus dan L. erythropterus) serta ikan kurisi Bali (Pristipomoides multidens dan $P$. typus) yang tertangkap oleh alat tangkap pukat harimau (trawl net). Ikan kurisi Bali termasuk famili Lutjanidae yang di daerah Tual dan Laut Timor ditangkap secara ekstensif oleh nelayan tradisional dengan menggunakan pancing ulur dan pancing rawai oleh perikanan industri. Sebagai gambaran total hasil tangkapan kakap merah (Lutjanus malabaricus, L. erytropterus termasuk Pristipomoides spp.) di Indonesia kurang lebih 53.000 ton pada tahun 1995 dan turun sebesar 6.000 ton dibandingkan tahun 1994 (Suboko, 1997). Oleh karena itu untuk menjaga kesinambungan hasil tangkapan dan menjaga jangan sampai terjadi lebih tangkap maka salah satu aspek penting untuk diketahui adalah aspek biologi reproduksi antara lain: fekunditas dan musim pemijahan. Dengan diketahuinya aspek reproduksi memungkinkan dapat diterapkan pengaturan musim penangkapan ataupun

\footnotetext{
Peneliti pada Balai Besar Riset Perikanan Budi daya Laut, Gondol

Peneliti pada Balai Pengkajian Teknologi Pertanian Ambon, Ambon

Peneliti pada Balai Pengkajian Teknologi Pertanian Ambon, Ambon
}

ukuran minimum ikan yang boleh ditangkap. Tujuan penelitian ini adalah untuk mengetahui fekunditas, hubungan panjang berat, ukuran pertama kali matang gonad ikan kurisi Bali ( $P$. typus). Informasi ini diharapkan dapat digunakan sebagai bahan pertimbangan bagi pengelolaan sumber daya ikan secara lestari dan berkesinambungan

\section{BAHAN DAN METODE}

\section{Sampling}

Ikan kurisi Bali (Gambar 1) diperoleh dari hasil tangkapan nelayan pancing ulur di perairan sekitar Kepulauan Kei Kecil, Maluku Tenggara (Lampiran 1) yang didaratkan di pasar ikan Tual. Sampling dilakukan setiap bulan dari bulan Juni 1999 sampai dengan bulan April 2000. Ikan yang diperoleh diukur panjang totalnya $(\mathrm{cm})$ dan beratnya (gr) serta diambil gonadnya dan diawetkan dengan formalin $10 \%$.

\section{Analisa Gonad}

Gonad dikering-udarakan dan ditimbang dengan ketelitian 0,001 gr kemudian dipotong melintang lalu disimpan dalam alkohol $70 \%$. Selanjutnya dibuat 


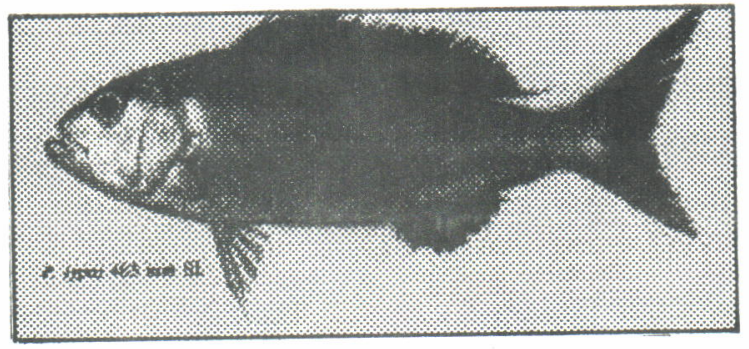

Gambar 1. Ikan kurisi Bali, Pristipomoides typus (Sumber: Allen, 1985)

Figure 1. Sharptooth snapper, Pristipomoides typus (Source: Allen, 1985).

preparat histologi dengan irisan setebal 6 mikron dan diberi pewarnaan hematoxylen dan eosin (Luna, 1968).

Preparat kemudian diamati di bawah mikroskop untuk ditentukan tingkat kematangannya. Gonad tersebut dikelompokkan menurut tingkatnya berdasarkan klasifikasi Hunter \& Goldberg (!980); Cyrus \& Blaber (1984); Andamari et al. (1998). Kriteria tingkat kematangan adalah sebagai berikut:

Tingkat I Belum berkembang (terdapat oogonia)

Tingkat II Berkembang (pre-vitellogec oocytes)

Tingkat III Permulaan matang (telur mulai terbentuk; sebagian belum terwarnai)

Tingkat IV Hampir matang (terbentuk chorion)

Tingkat $V$ Matang/hidrasi (telur berwarna merah merata; hidrasi)

Tingkat VI Salin (terdapat atreasia; terdapat postvitellogenic follicles)

Setelah ditentukan tingkat kematangannya maka gonad yang mempunyai tingkat kematangan IV dan $\mathrm{V}$ dihitung jumlah telurnya untuk menentukan fekunditas. Jumlah telur setiap angkatan (batch fecundity) diduga berdasarkan rumus Bagenal (1978) sebagai berikut:

$$
F=(W g N s) \cdot n
$$

di mana:

$$
\text { F : batch fencundity }
$$
Wg
Ws : berat gonad sub sampel (Gri)
n : jumlah telur dalam sub sampel

Fekunditas relatif dihitung dari jumlah telur per satuan berat menurut Effendi (1997).

\section{Hubungan Panjang-Berat}

Menurut Effendi (1997) berat ikan dapat dianggap sebagai suatu fungsi dari panjang dan biasanya mengikuti hukum kubik. Apabila ikan tersebut tidak mengikuti hukum kubik maka pertumbuhan ikan tersebut bersifat alometrik (tidak sama dengan 3 ).

Rumus hubungan panjang berat (Royce, 1984) adalah sebagai berikut:

$$
\begin{aligned}
W & =a L^{b} \\
\text { di mana: } & \\
W & =\text { berat }(g r) \\
L & =\text { panjang }(\mathrm{cm}) \\
a \text { dan b } & =\text { konstanta }
\end{aligned}
$$

\section{HASIL DAN BAHASAN}

Dari hasil sampling sebanyak 150 ekor, 86 ekor di antaranya gonadnya sudah mulai berkembang. Deskripsi panjang dan berat ikan contoh dapat dilihat pada Tabel 1.

\begin{tabular}{lcccc}
\hline & $\begin{array}{c}\text { Minimum } \\
\text { Minimum }\end{array}$ & $\begin{array}{c}\text { Maksimum } \\
\text { Maximum }\end{array}$ & $\begin{array}{c}\text { Rata-rata } \pm \text { SE } \\
\text { Average } \pm \text { SE }\end{array}$ & N \\
\hline $\begin{array}{l}\text { Panjang Total } \\
\begin{array}{l}\text { Total Length } \\
\text { (cm) }\end{array}\end{array}$ & 15.5 & 64.7 & $34.4 \pm 2.81$ & 150 \\
$\begin{array}{l}\text { Berat } \\
\text { Weigth } \\
\text { (gr) }\end{array}$ & 42.1 & 2875 & & \\
\hline
\end{tabular}




\section{Hubungan Panjang-Berat}

Dari 150 ekor contoh ikan tersebut sebagai fungsi panjang-beratnya

$$
\begin{aligned}
& W=0,024 L^{2,766} \\
& R^{2}=0,97
\end{aligned}
$$

Berdasarkan uji $t$ nilai b tidak sama dengan 3 berarti ikan kurisi Bali bersifat alometrik yaitu pertambahan panjang lebih cepat dari pada pertambahan beratnya, hal ini sesuai dengan bentuk ikan kurisi Bali yang kurus dan panjang (Gambar 2).

\section{Tingkat Kematangan Gonad dan Fekunditas}

Dari 86 buah gonad ikan contoh terdapat 42 gonad jantan dan 44 gonad betina, jadi bisa disimpulkan bahwa perbandingan ikan jantan dan ikan betina untuk ikan kurisi Bali seimbang (berdasarkan uji khiquadrat). Tingkat kematangan gonad selama pengamatan dapat dilihat pada Tabel 2 .
Dari pengamatan tingkat kematangan gonad secara histologis terlihat bahwa ikan bersifat asinkronus yang berarti dalam satu gonad terdapat beberapa tingkatan sehingga dapat memijah beberapa kali dalam satu musim pemijahan (Gambar 3). Hal ini sesuai dengan penelitian Min et al. (1977) dan Kikkawa (1984) daiam Lloyd (1994).

Pada bulan Januari, Pebruari dan April terdapat gonad betina yang telah matang dan pada bulan April terdapat satu ekor yang hidrasi, tetapi tidak ditemukan yang telah memijah. Dari 4 gonad betina yang telah matang tersebut dihitung fekunditasnya. Fekunditas per angkatan berkisar antara 70 ribu hingga 204 ribu butir (rata-rata 155.826 butir). Sedangkan fekunditas relatif berkisar dari 115 sampai dengan 340 butir (rata-rata 180 butir). Untuk lebih jelasnya hubungan fekunditas dan panjang ikan dapat dilihat pada Gambar 4. Fekunditas $P$. typus dari Tual ini lebih kecil bila dibandingkan dengan penelitian Lloyd (1994) yang menyebutkan $P$. typus dari Laut Timor berkisar antara 800 ribu sampai 2,1 juta butir (batch fecundity).

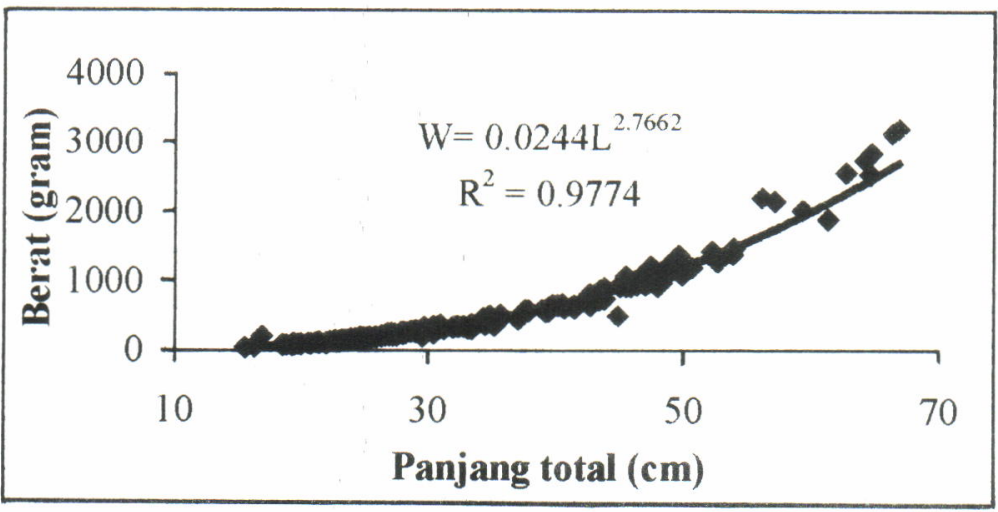

Gambar 2. Hubungan panjang-berat ikan kurisi Bali ( $P$. typus) dari Tual $(n=150)$

Figure 2. Length-weight relationship of sharptooth snapper (P. typus) from Tual $(n=150)$

Tabel 2. Tingkat kematangan gonad (TKG) ikan kurisi Bali ( $P$. typus) di Tual pada bulan Juli 1999 sampai dengan bulan April 2000

\begin{tabular}{|c|c|c|c|c|c|c|c|c|}
\hline \multirow{2}{*}{$\begin{array}{l}\text { Bulan } \\
\text { Month }\end{array}$} & \multirow{2}{*}{$\begin{array}{l}\text { Jenis } \\
\text { Kelamin } \\
\text { Sex }\end{array}$} & \multicolumn{6}{|c|}{$\begin{array}{l}\text { Tingkat Kematangan Gonad (TKG) } \\
\text { Gonad Maturity (GM) }\end{array}$} & \multirow{2}{*}{$\begin{array}{c}\text { Jumlah } \\
\text { Total }\end{array}$} \\
\hline & & $\mathrm{I}$ & II & III & IV & V & VI & \\
\hline \multirow{2}{*}{$\begin{array}{l}\text { Juli } 99 \\
\text { July } 99\end{array}$} & Jantan/Male & - & - & 1 & 3 & 2 & - & 6 \\
\hline & BetinalFemale & - & 7 & - & - & - & - & 7 \\
\hline \multirow{2}{*}{$\begin{array}{l}\text { Agustus } 99 \\
\text { August } 99\end{array}$} & Jantan/Male & - & - & - & 2 & 1 & - & 3 \\
\hline & BetinalFemale & - & 2 & - & - & - & - & 2 \\
\hline \multirow{2}{*}{$\begin{array}{l}\text { Nopember } 99 \\
\text { November } 99\end{array}$} & Jantan/Male & - & - & 1 & 4 & 5 & - & 10 \\
\hline & Betina/Female & - & 7 & 1 & - & - & - & 8 \\
\hline \multirow{2}{*}{$\begin{array}{l}\text { Desember } 99 \\
\text { December } 99\end{array}$} & Jantan/Male & - & - & 3 & 2 & 2 & - & 7 \\
\hline & Betina/Female & - & 5 & - & - & - & - & 5 \\
\hline \multirow{2}{*}{$\begin{array}{l}\text { Januari } 00 \\
\text { January } 00\end{array}$} & Jantan/Male & - & - & 1 & - & 2 & - & 3 \\
\hline & BetinalFemale & - & 7 & - & 1 & - & - & 8 \\
\hline \multirow{2}{*}{$\begin{array}{l}\text { Pebruari } 00 \\
\text { February } 00\end{array}$} & Jantan/Male & - & - & 1 & 1 & - & - & 2 \\
\hline & Betina/Female & - & 3 & - & 1 & - & - & 4 \\
\hline \multirow{2}{*}{$\begin{array}{l}\text { April } 00 \\
\text { April } 00\end{array}$} & Jantan/Male & - & - & - & 3 & 8 & - & 11 \\
\hline & BetinalFemale & - & 8 & - & 1 & 1 & - & 10 \\
\hline
\end{tabular}

Tabel 2. Gonad maturity stage of sharptooth snapper (P. typus) in Tual from July 1999 until April 2000 

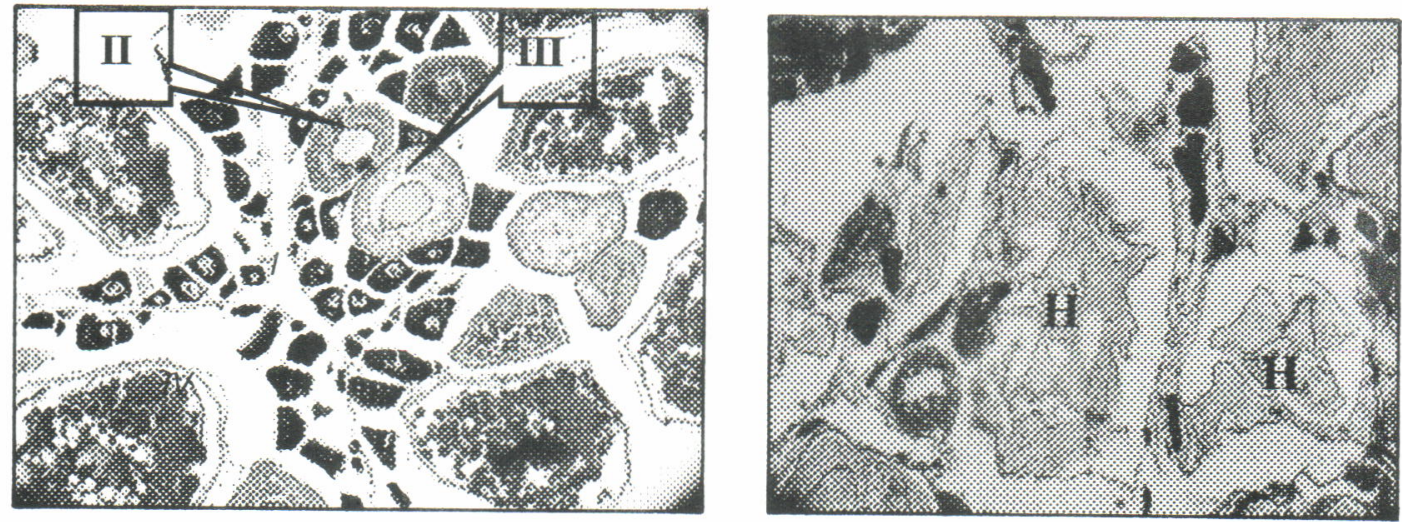

Gambar 3. Irisan gonad $P$. typus dengan bebagai tingkat kematangannya (H\&E $100 \mathrm{X}$ ).

Figure 3. Histological sections of the gonads of $\boldsymbol{P}$. typus showing the stage of maturity (H\&E $100 X)$.

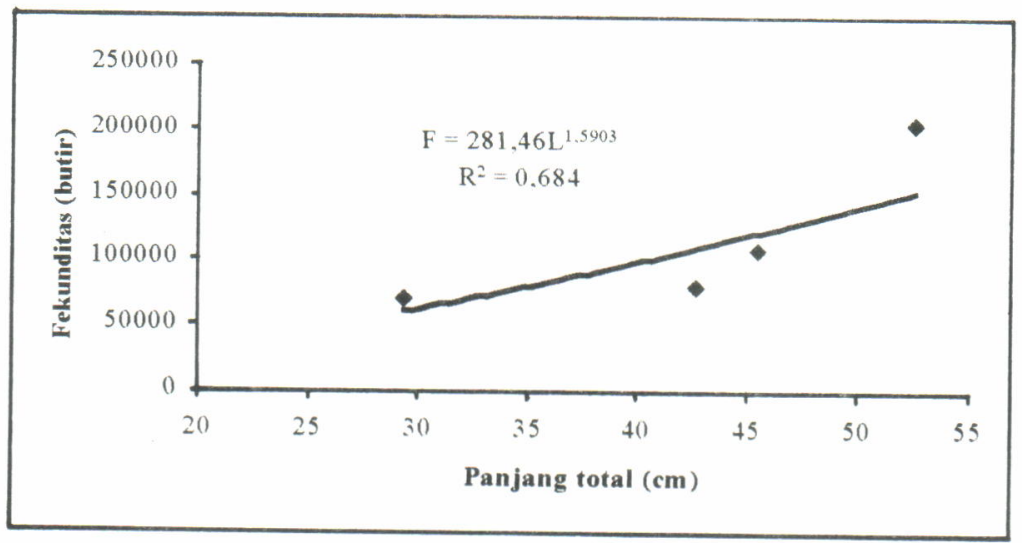

Gambar 4. Hubungan panjang total $(\mathrm{cm})$ dan fekunditas (butir) ikan kurisi Bali ( $P$. typus) dari perairan Kei Figure 4. Total length $(\mathrm{cm})$ and fecundity (ind) relationship of sharptooth snapper (P. typus) from Kei Kecil
waters.

Perbedaan yang diperoleh dari penelitian ini kemungkinan berbeda ukuran ikan. Fekunditas ada hubungannya dengan ukuran ikan, yang dinyatakan bahwa semakin besar ikan akan mempunyai gonad semakin besar pula sehingga batch fecundity juga semakin besar.

Dalam penelitian ini hanya terdapat 4 ekor ikan yang matang gonad (TKG IV dan V dengan diameter oosit berkisar dari $350 \mu$ sampai $600 \mu$ ) dan relatif masih kecil ukurannya. $P$. typus dapat mencapai berat sampai 5 $6 \mathrm{~kg}$.

Dari 150 ekor ikan contoh, gonad jantan maupun betina mulai dapat diamati pada ikan dengan berat 200 gram dan panjang total $25 \mathrm{~cm}$ dengan tingkat kematangan gonad II. Menurut Allen (1985) pertama kali matang gonad ikan $P$. typus pada panjang total 28 $\mathrm{cm}$, sedangkan dalam penelitian ini dari 4 ekor ikan yang matang gonad yang terkecil mempunyai panjang total $29,4 \mathrm{~cm}$ dan berat 206,9 gram. Dalam penelitian ini belum dapat ditentukan ukuran pertama kali matang gonad disebabkan jumlah sampel yang terlalu sedikit.
Musim pemijahan ikan $P$. typus mempunyai waktu yang panjang dengan dua atau lebih puncak pemijahan (Min et al., 1977). Sedangkan menurut Brouard dan Grandperrin (1985), di Vanuatu $P$. muttidens memijah sepanjang tahun dengan puncak pemijahan antara Desember dan Januari. Dalam penelitian ini meskipun hanya sedikit jumlah sampel yang diperoleh dan juga belum ada data sepanjang tahun tetapi dapat memberikan gambaran bahwa kemungkinan pemijahan terjadi pada bulan Pebruari sampai Mei, karena gonad yang matang pada bulan tertentu diduga akan memijah pada bulan berikutnya.

\section{KESIMPULAN}

Ikan kurisi Bali (Pristipomoides typus) mempunyai perkembangan oosit yang asinkronus dan dapat memijah beberapa kali. Fekunditas relatif berkisar dari 100 sampai dengan 340 butir dengan rata-rata 180 butir, sedangkan batch fecundity berkisar antara 70 ribu sampai dengan 204 ribu. Gonad mulai berkembang baik pada ikan jantan dan betina pada panjang total $25 \mathrm{~cm}$ dan berat 200 gram. 


\section{UCAPAN TERIMA KASIH}

Pada kesempatan ini penulis menyampaikan terima kasih yang sebesar-besarnya kepada Sdr. Mujimin yang telah menyiapkan preparat histologi dan kepada Sdr. Muhamad Syukur selaku Pimpinan Bagian Proyek Pembinaan Kelembagaan Penelitian dan Pengembangan Pertanian/ARMP \| Maluku sehingga penelitian ini dapat terlaksana.

\section{DAFTAR PUSTAKA}

Allen, G.R. 1985. Snappers of the world. An annotated and illustrated catalogue of lutjanid species known to date. FAO species catalogue. Vol. 6.

Andamari, R., M. Farmer, U. Chodriyah, \& A.N. Susanto. 1998. Gonad maturity stages of anchovies (Encrasicholina heterolobus) from Bacan Island. Indonesian Fisheries Research Joumal, 6 (2): 4751.

Bagenal, T.B. 1978. Methods for assessment of fish production in fresh water. IBP. Handbook (3) Blackwell Scientific Publications, Oxford, p. 253

Brouard, F., \& Grandperrin R. 1985. Deep-bottom fishes of the outer reef slope in Vanuatu South Pacific Commission 17 th Regional Technical Meeting on Fisheries. Noumea, New Caledonia.
Cyrus, D.P. \& Blaber, S.J.M. 1984. The reproductive biology of Gerres (Teleostei) Bleeker 1859, in Natal estuaries. J. Fish. Biol, 24: 491-504.

Effendie, M.I. 1997. Biologi perikanan. Yayasan Pustaka Nusatama. Yogyakarta.

Hunter, J.R. \& Goldberg, S.R. 1980. Spawning incidence and batch fecundity in northern anchovy Engraulis mordax. Fish. Bull. U.S., 77:641-652

Lloyd, J.A. 1994. Goldband snapper in the northern territory fishery. Fishery Report, 31. Northern Territory Dept. of Primary Industry and Fisheries, Darmin.

Luna, L.G. 1968. Manual of histological staining methods of the armed forces. Institute of Pathology. 3 rd. ed. McGraw-Hill, N.Y.

Min, T.S., Senta, T., \& Supongpan S. 1977. Fisheries biology of Pristipomoides spp. (Family Lutjanidae) in the South China Sea and its adjacent waters. Singapore J. Pri.ind., 5 (2): 96-115.

Royce, W.F. 1984. Introduction to the practice of fishery science. Academic Press. California, USA, 423 pp.

Suboko, B. 1977. Indonesian fisheries industry needs and opportunities. Paper presented to The AsiaPacific Fishing Conference and Exhibition, Cairns, Australia, 7-10 July 1997. Indonesian Fisheries Federation. 
Lampiran 1. Lokasi sampling ikan kurisi Bali (P. typus) di Tual, Kepulauan Kei. Appendix 1. Map of the sampling location P. typus, in Tual, Kei Archipelago.

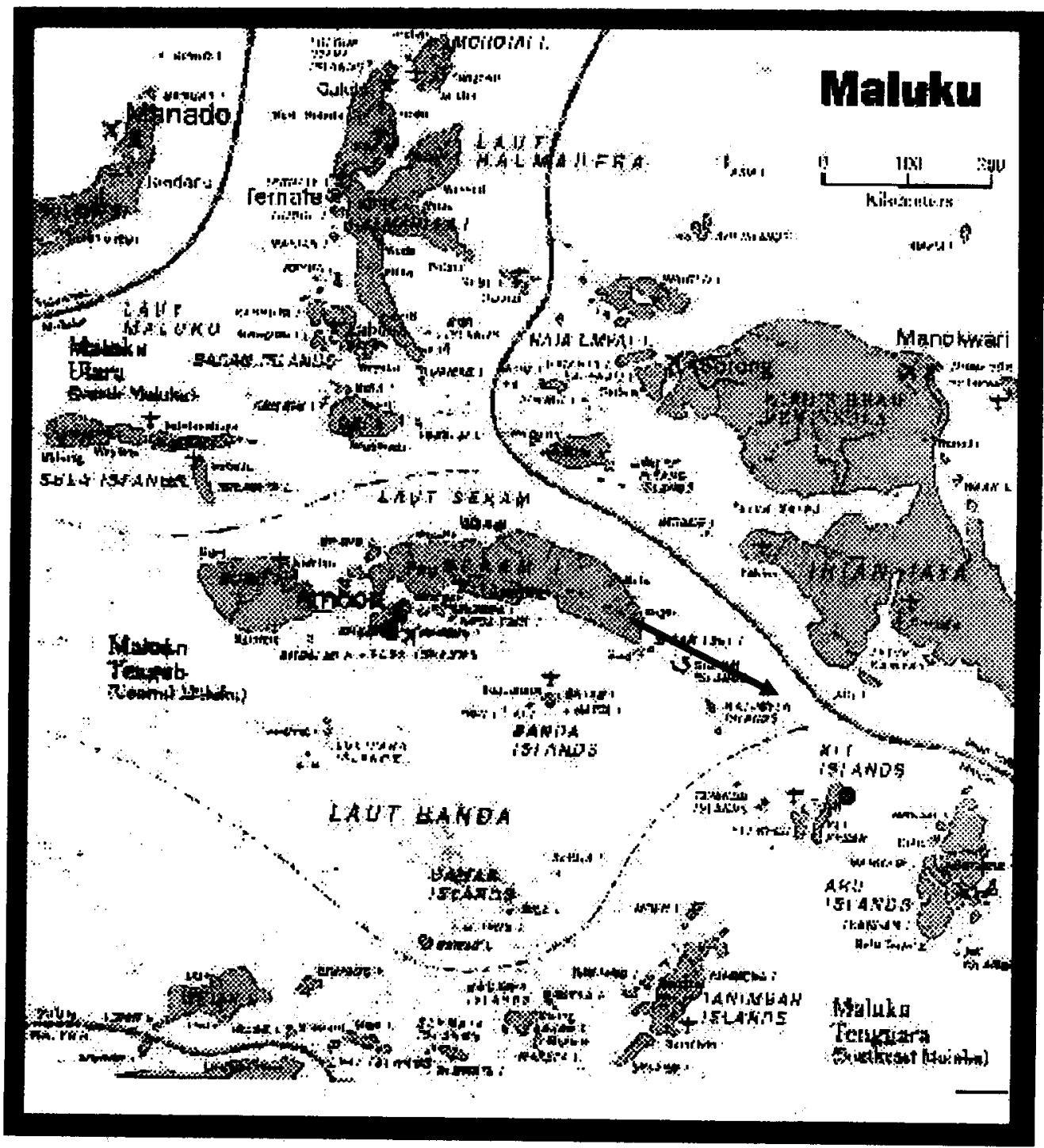

